\title{
Control of the Response Speed of the Hydraulic Pressure for Hydraulic Brake System
}

\author{
Zhiwei Cao ${ }^{1, a}$, Shun Peng ${ }^{2, b}$ and Kaijun $\mathrm{Du}^{3, \mathrm{c}}$ \\ ${ }^{1}$ CRRC Qingdao Sifang CO., Ltd., Qingdao266111,China \\ ${ }^{2}$ Institute of Railway and Urban Mass Transit,Tongji University,Shanghai, China \\ ${ }^{3}$ CRRC Qingdao Sifang CO., Ltd., Qingdao266111, China \\ b1553055597@qq.com
}

\begin{abstract}
Keywords: hydraulic brake system; response speed of pressure; pump displacement; AMESim Abstract. To study the response speed of the hydraulic pressure of hydraulic brake system, a hydraulic unit was taken as an example, and the structural principle of the key components was analyzed. Then the model of the hydraulic unit was established by AMESim for simulation and analysis, and variable-controlling approach was used to figure out how the parameters of the hydraulic unit impact the response speed of the hydraulic pressure. The result shows that the pump displacement and the size of oil return port of the regulating valve impact the pressure response speed significantly. The optimal pump displacement of this hydraulic unit is $0.3 \mathrm{ml} / \mathrm{r}$, and the optimal diameter of oil return port is $1 \mathrm{~mm}$.
\end{abstract}

\section{Introduction}

With the increasing number of hydraulic brake system used in urban rail vehicles, too large brake impulse becomes a problem to be solved because the liquid cannot be compressed. Heping Li and Xiaohui Yan have pointed out that the acceleration of brake and braking impulse are major impacts of passenger comfort of EMU[1]; Mingmin Duan and Wang Wei have studied the relationship between the acceleration of brake and braking impulse, and and have put forward the control method for air brake and composite brake of subway brake system; Peishu Li have analyzed the realization of impulse control under different braking conditions and the impact of impulse control on other braking functions.In this parper, a hydraulic unitwas used as an example, and the principle of the hydraulic unit was analyzed.Then simulation analysis model was established by AMESim. In order to control the impulse, the relationship between the response speed of pressure and the parameters of hydraulic brake system was studied.Finally, the optimal parameters of the hydraulic unit are determined.

\section{The basic working principle}

The structural principle of this hydraulic unit is shown in Figure 1. It can be divided into two pieces. The left part shown in Figure 1 is the pressure generation module, and the right part is the pressure control module. The passive brake clamp are operated by the pressure generation and control of the hydraulic unit, and then brake or release are made. When the pressure reduces, the train brakes; and when the pressure rises, and the train gets released. 


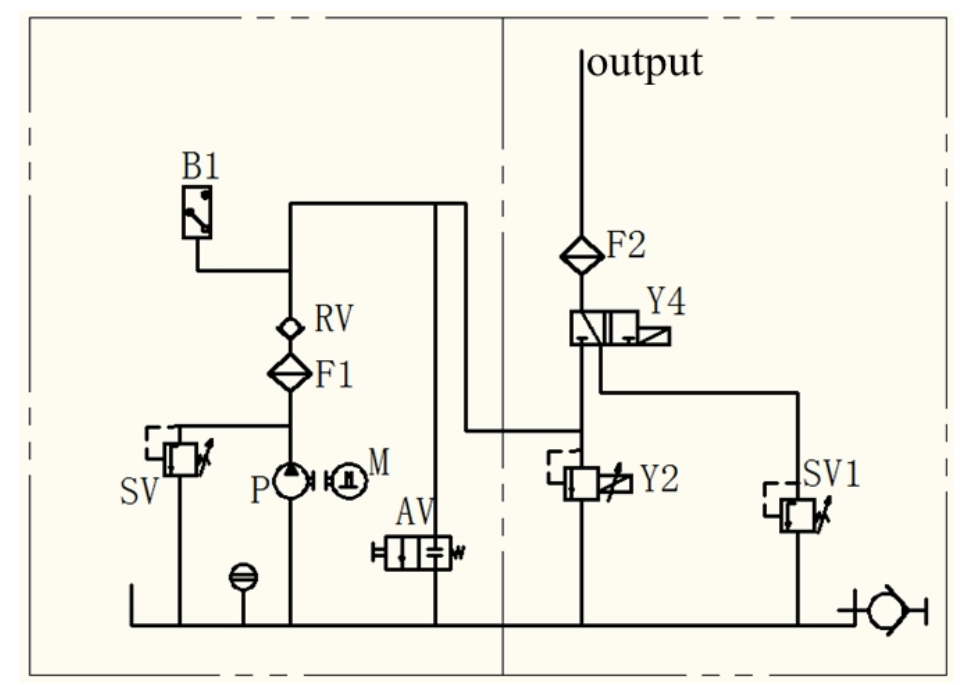

P_-Pump; M-Motor; SV—-Safety valve; F1、F2—-Hydraulic filter; RV__Check valve; B1_-Pressure switch; Y2_-Regulating valve;

SV1_-Regulating valve 1; Y4_Emergency valve

Fig.1 The structural principle of the hydraulic unit

The generation of pressure: When the control signal is received, the motor(M) starts, and drives the hydraulic pump(P). Then the hydraulic oil in the oil tank is sucked into the brake pipe through the filter(F1) and the check valve(RV), and the pressure of the brake pipe is increased. When the pressure rise to the value limited by the pressure switch(B1), the motor cut off and the rise of the pressure stop. At that moment the maximum current shut down the regulating valve(Y2). Shown in Figure 1, The safety valve(SV) is aim to prevent the system pressure from reaching too high value, and the check valve to prevent hydraulic oil of the brake tube from being back to the oil tank.

The control of pressure: Emergency valve (Y4) is normally powered on, and the output pressure (the pressure of the brake cylinder) of this hydraulic unit are adjusted by the regulating valve(Y2). When the current of the the regulating valve decreases, the pressure drops, otherwise the pressure rises. When the emergency valve is powered off, the output pressure of the hydraulic unit is determined by the regulating valve (SV1), and at that moment, the train brake.

\section{Modeling}

The structural principle of the regulating valve is shown in Figure 2(a). The valve core is balanced between the spring preload and the oil pressure. When $\mathrm{p}^{*} \mathrm{~A}>\mathrm{F}_{\mathrm{s}}$, the core moves up, and the valve seat turn on. Then the oil drains back to the tank and the oil pressure drops, until $\mathrm{p}^{*} \mathrm{~A} \leq \mathrm{F}_{\mathrm{s}}$. That is to say, the input pressure of the valve is limited by the spring preload. According to this working principle of the regulating valve, the simulation model, shown in Figure 2(b), is established by using AMESim. 


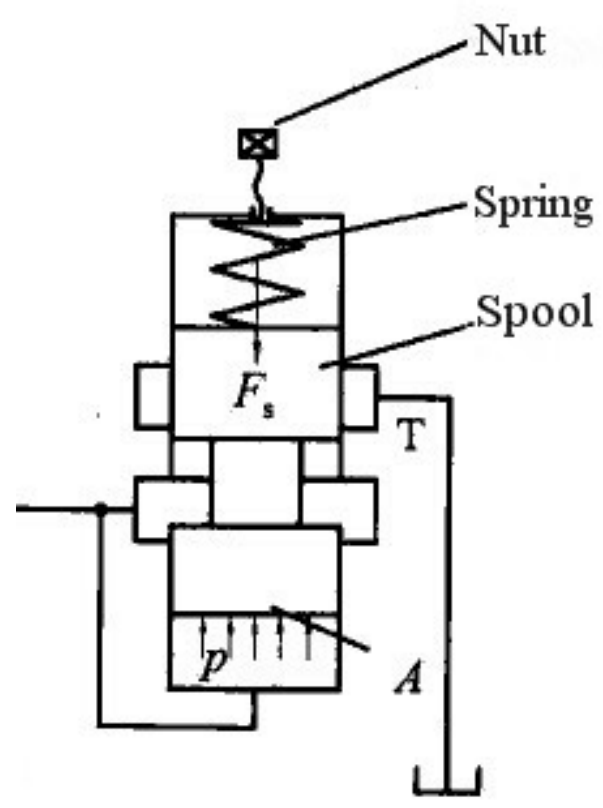

(a)

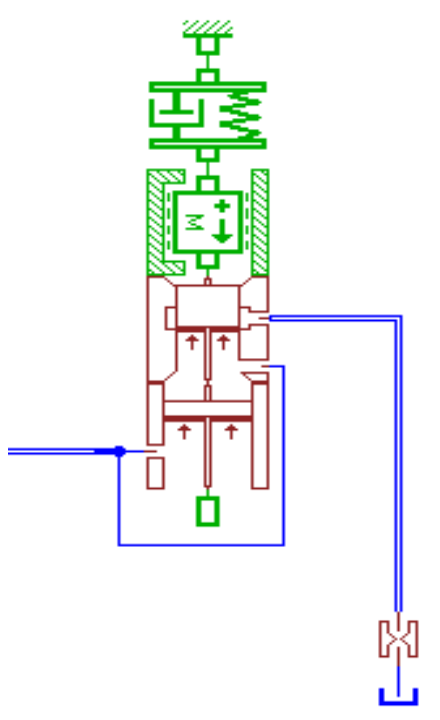

(b)

Fig.2 The structural principle of the regulating valve

Using similar method, other components of the hydraulic unit can be modeled. And some simulation models can be directly selected in the AMESim component library. The model of the whole hydraulic unit is shown in Figure 3.

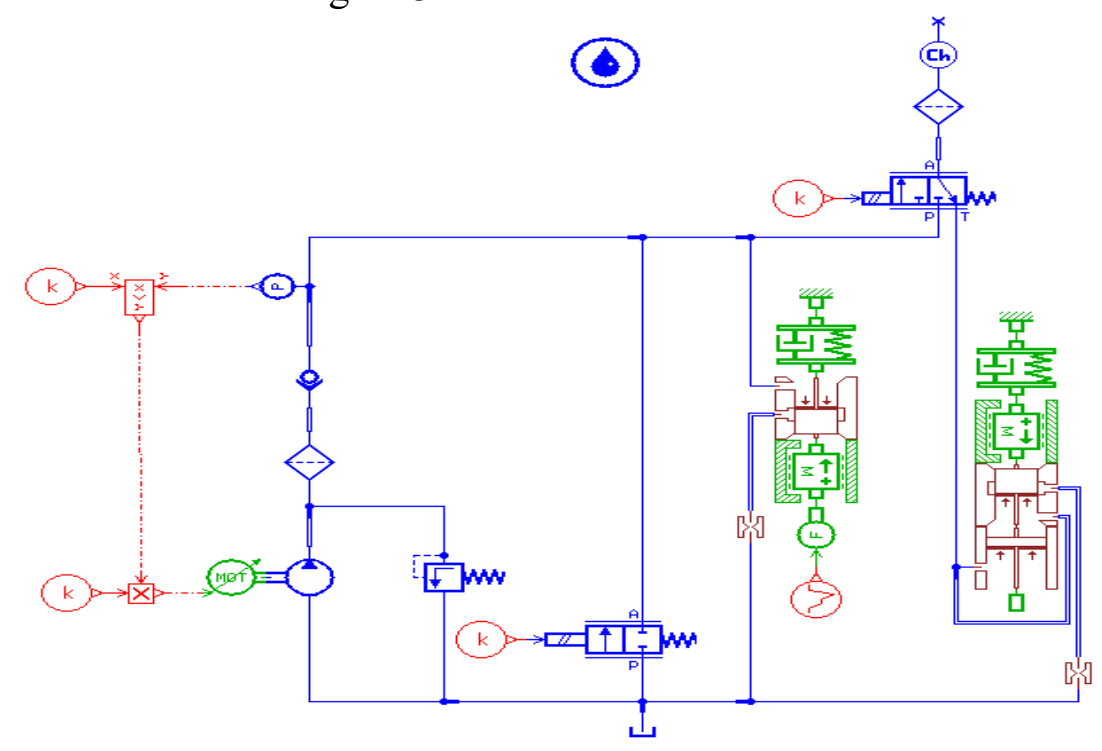

Fig.3 The model of the whole hydraulic unit in AMESim

Parameter settings are shown in Table 1.

Table 1 Parameter settings of the simulation model

\begin{tabular}{|c|c|}
\hline Parameter & The value \\
\hline Rotary speed of motor & $3000 \mathrm{r} / \mathrm{min}$ \\
\hline $\begin{array}{c}\text { Typical speed of pump、pump } \\
\text { displacement }\end{array}$ & $3000 \mathrm{r} / \mathrm{min} 、 2.5 \mathrm{~mm}$ \\
\hline Diameter of filter orifice & F1 $-30 \mu \mathrm{mm} ; \mathrm{F} 2-60 \mu \mathrm{mm}$ \\
\hline Flow of check valve & $10 \mathrm{~L} / \mathrm{min}$ \\
\hline Relief valve cracking pressure & $170 \mathrm{bar}$ \\
\hline Brake cylinder volume & $13 \mathrm{~mL}$ \\
\hline Oil type & ESSO UNIVIS HVI26 \\
\hline
\end{tabular}




\section{Control of pressure response speed}

Two performance index of the control system are as follows: control accuracy and response time. In this brake control system, it means the pressure rising (or falling) time and the accuracy of the pressure control. In the hydraulic brake control unit, it is wrong that the shorter the response time is, the better the hydraulic unit is, because if the pressure rises (or falls) too fast, the longitudinal impulse of the train may exceeds the limit.

Unlike air brake systems, the pressure rising time of the hydraulic brake system is almost not affected by the middle hydraulic tube (such as the pipe size or intermediate chamber size), because the hydraulic oil can not be compressed. And we generally control the response speed of pressure by controlling the pump displacement and the size of oil return port of the regulating valve in the hydraulic system whose implementation of components is hydraulic cylinder.

First of all,simulate this model under various pump displacement. The curves of hydraulic pressure in the brake cylinder are shown in Figure 4.

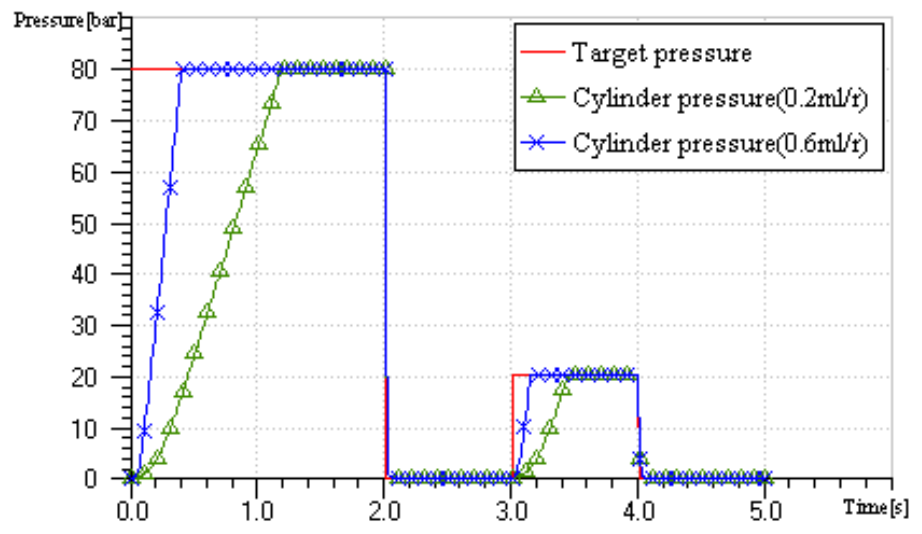

Fig.4 Impact of the pump displacement on the pressure response speed

Two curves has a significant difference on the pressure rising stage in Figure 4. It illustrates that the pump displacement have huge impact on the pressure rising speed. The greater the displacement is, the faster the pressure rises. Beside, from pressure falling stage in Figure 4, we can see that there is no significant difference between two curves. It illustrates that the pump displacement almost not affect the pressure falling speed.

Then, change the diameter of oil return port of the regulating valve and simulate this model. The curves of hydraulic pressure in the brake cylinder are shown in Figure 4.

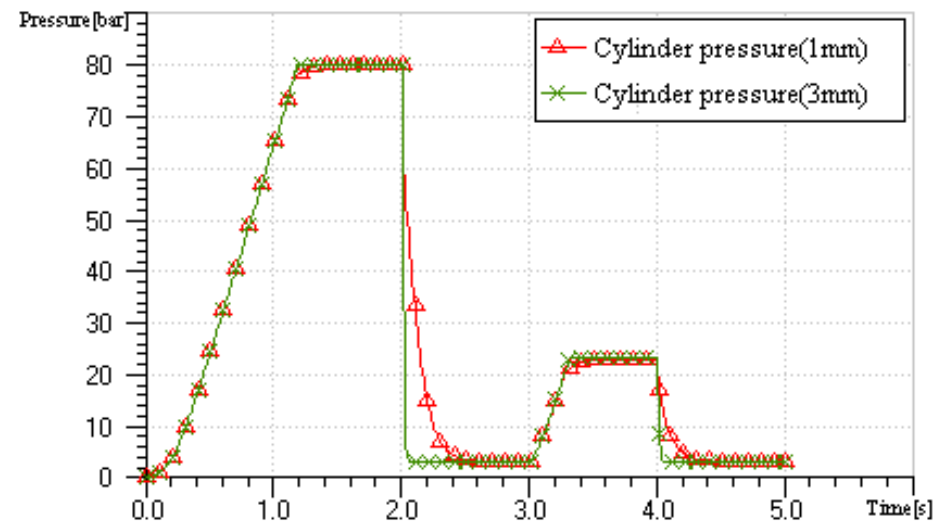

Fig.5 Impact of the diameter of oil return port on the pressure response speed

As can be seen in Figure 5, pressure falling speed depends on the size of oil return port of the regulating valve. The greater the diameter of oil return port is, the faster the pressure falls.

In order to avoid the impulse exceeded, the pressure rising (or falling) speed can not be too large. And under the premise of not exceeding the maximum impulse, the response speed of the pressure should be improved as much as possible. So there are optimal values of both the pump displacement and the size of oil return port of the regulating valve. According to the relevant information, the 
emergency braking impulse of the low floor train is limited to $8 \mathrm{~m} / \mathrm{s}^{3}$. The emergency braking acceleration of this vehicle is $2.8 \mathrm{~m} / \mathrm{s}^{2}$, and the brake cylinder pressure need drop 25bar in this condition. So according to the impulse limit, the pressure falling time needs at most $0.35 \mathrm{~s}$, and the pressure falling speed is $71 \mathrm{bar} / \mathrm{s}$. After many simulation for debugging, the result is shown in the table 2. According to this table, the final pump displacement is selected as $0.3 \mathrm{ml} / \mathrm{r}$, and the diameter of oil return port of the regulating valve is selected as $1 \mathrm{~mm}$. In this setting, the curve of hydraulic pressure in the brake cylinder is shown in Figure 6.

Table 2 Braking impulse under different parameter settings

\begin{tabular}{|c|c|c|c|c|c|}
\hline Number of times & 1 & 2 & 3 & 4 & 5 \\
\hline Pump displacement $(\mathrm{ml} / \mathrm{r})$ & 1 & 0.5 & 0.4 & 0.3 & 0.2 \\
\hline oil return port diameter $(\mathrm{mm})$ & 5 & 3 & 2 & 1 & 0.8 \\
\hline $\begin{array}{c}\text { The pressure response speed } \\
(\mathrm{bar} / \mathrm{s})\end{array}$ & 500 & 151 & 122 & 101 & 83 \\
\hline Braking impulse $(\mathrm{m} / \mathrm{s} 3)$ & 37.6 & 11.4 & 9.2 & 7.6 & 6.2 \\
\hline
\end{tabular}

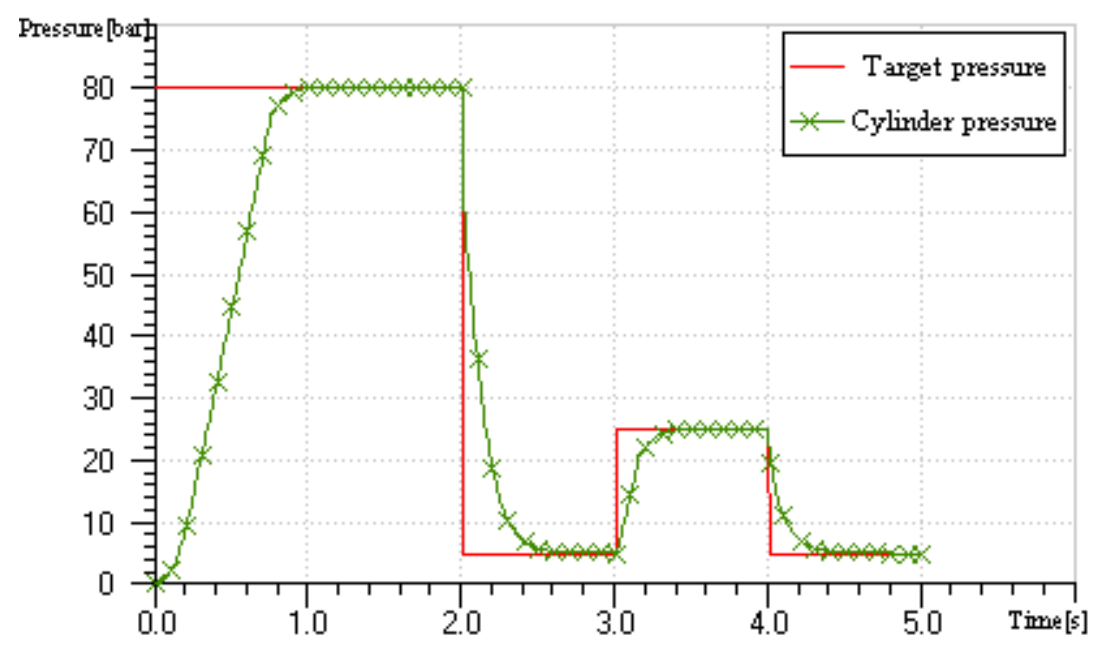

Fig.6 The curve of hydraulic pressure in the brake cylinder

\section{Conclusions}

A hydraulic unit was taken as an example, and the structure principle of the key components was analyzed in this paper. Then the simulation model of the hydraulic unit was established by AMESim, and the impact of some key parameters on the pressure response speed was studied. Two conclusions are as follow:

1. The pump displacement impacts the pressure rising speed greatly; and the greater the displacement is, the faster the pressure rises. But pressure falling speed depends on the the size of oil return port of the regulating valve; and the greater the diameter of oil return port is, the faster the pressure falls.

2. Considering the impact of impulse, the pump displacement should be selected as $0.3 \mathrm{ml} / \mathrm{r}$ in this hydraulic unit, and the diameter of oil return port of the regulating valve should be selected as $1 \mathrm{~mm}$.

\section{References}

[1] Heping Li, Xiaohui Yan. Passenger comfort and brake control of EMU [J]. RAILWAY LOCOMOTIVE \&CAR, 2011,31(5): 111-114.

[2] Mingmin Duan, Wei Wang. A brief discussion for brake control and impact of metro [J]. RAILWAY LOCOMOTIVE \&CAR, 2011,31(6): 63-65.

[3] Jiwei Wang. Hydraulic transmission (the second edition).Beijing:China machine press, 2007.

[4] Peishu Li. The jerk limit control of braking system [J]. Rolling Stock, 2015,53(3): 12-15. 